\title{
Heat Transfer and Energy Performance of a PVA Wall Tile Containing Macro-Encapsulated PCM
}

\author{
Pin-Feng Liu ${ }^{1,+}$, Yi-Pin Lin ${ }^{2,+}$, Chun-Ta Tzeng ${ }^{1,+}$ and Chi-Ming Lai ${ }^{3, *}$ \\ 1 Department of Architecture, National Cheng Kung University, Tainan 701, Taiwan; \\ binfeng511@gmail.com (P.-F.L.); ctmt@mail.ncku.edu.tw (C.-T.T.) \\ 2 Department of Creative Design, National Yunlin University of Science and Technolog, Yunlin 64002, Taiwan; \\ purple5028@gmail.com \\ 3 Department of Civil Engineering, National Cheng Kung University, Tainan 701, Taiwan \\ * Correspondence: cmlai@mail.ncku.edu.tw; Tel.: +886-6-275-7575 (ext. 63136) \\ + These authors contributed equally to this work.
}

Academic Editor: Hossam A. Gabbar

Received: 23 April 2016; Accepted: 12 August 2016; Published: 18 August 2016

\begin{abstract}
This study integrated building material engineering, building construction practices, and heat transfer mechanisms to develop a polyvinyl acetate (PVA) based wall tile, containing macro-encapsulated phase change material (macro-encapsulated PCM, macroPCM) and PVA. The heat transfer characteristics and energy performances of the proposed prototype were investigated experimentally. The results indicated that the PVA-based macroPCM wall tile is suitable for use in exterior walls to enhance the thermal performance. The tile shows a lower heat indoor heat flux than other tested similar building materials and increases the time lag of peak load, effectively shifting the summer peak demand.
\end{abstract}

Keywords: heat transfer; energy; phase change material; macro-encapsulated phase change material; polyvinyl acetate

\section{Introduction}

During melting or solidification processes, a phase change material (PCM) can effectively store or release a certain amount of latent heat. The temperature of a PCM can also be stably maintained during the latent heat transfer process. It possibly bridges the gap between energy availability and energy need. Therefore, a PCM is a feasible material choice in energy storage and thermal management applications. Applications for PCMs include thermal storage systems [1-3], integration with building materials for energy management [4-7], use as a working fluid [8], and use in fireproof engineering, among others. Comprehensive reviews on PCMs, including their thermophysical properties, long-term stability, impregnation methods, current building applications, and their thermal performance analyses, as well as on numerical simulations of buildings with PCMs, can be found in the literature [9-11].

Hasse et al. [12] investigated the temperature variations of honeycomb panels filled with paraffin wax PCM. Mahmoud et al. [13] experimentally investigated the effects of the PCM material, heat sink designs, and power levels on the performance of PCM-based heat sinks. The PCMs used were paraffin wax, inorganic hydrated salts, organic substances, and inorganic materials. Six heat sink designs were used, as follows: one with a single cavity, two with a parallel fin arrangement, two with a cross fin arrangement, and one with a honeycomb insert inside the single cavity. PCM may interact with the building structure and change the properties of the matrix materials, or leakage may be a problem over the lifetime of many years. However, micro-encapsulated PCM and macro-encapsulated PCM (mPCM and macroPCM respectively) may change this situation $[14,15]$ and becomes a promising material 
choice in building energy applications. The existing literature on energy performance investigations of decoration materials in buildings with $\mathrm{mPCM}$ or macroPCM capsules is still limited.

By incorporating macroPCM materials into wall construction, the through-wall heat transfer can hopefully be controlled with the absorption and release of PCM latent heat. This study proposed incorporating macroPCM capsules into polyvinyl acetate (PVA) to fabricate the wall tile. The heat transfer behavior and energy performance were then investigated experimentally.

\section{Research Method}

\subsection{Practice Consideration}

Before establishing the prototype, we first explored some practical aspects, including how to integrate the existing exterior or interior wall system with these macroPCM applications while not significantly increasing the cost or changing the existing building construction. The main function of building structures is to maintain the structural safety aspects; therefore, it is difficult to arbitrarily change the associated materials, dimensions, or construction methods. Achieving thermal insulation enhancement via altering the main structures can be problematic. Feasible locations for enhancing thermal insulation performance lie in the polishing layer, decoration layer, coating materials, or paints of the outer layer of main structures. Therefore, this study was conducted in an application context of reinforced concrete (RC) buildings, and the main investigation targets (i.e., feasible locations for thermal insulation enhancement) were the polishing and decoration layers outside the main RC structures. We used two decoration layer materials, macroPCM + mortar and macroPCM wall tile (hereafter, "macroPCM + PVA"), to replace close light pebbles and wall tiles that are commonly used in interior and exterior walls (Figure 1). Additionally, macroPCM + epoxy was used to replace the epoxy layer in the existing roof construction. Using the above materials involves simple construction processes. Based on discussions and interactions of our research team with the industry, all masons and insulation engineers accept the proposed materials. These materials are acceptable in terms of cost and are safe and weather-resistant.

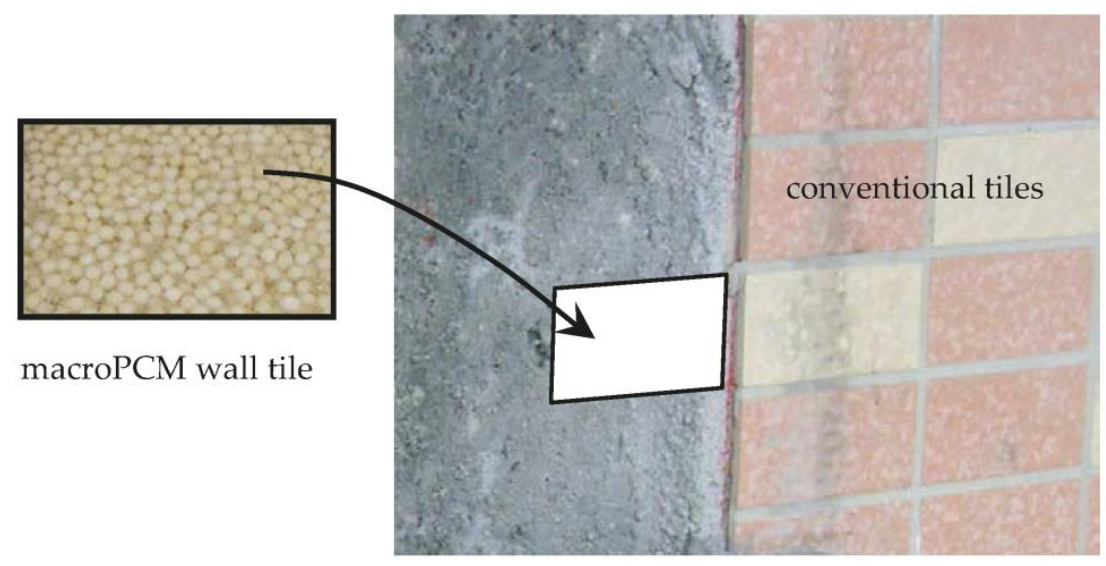

Figure 1. Possible installation locations of the PVA-based macroPCM wall tiles.

\subsection{Experimental Test Cell}

Figure 2 presents a photo of the investigated target and the physical model. To reduce heat loss to the environment, the tested module was positioned with a Balsa board box (with a board thickness of $2 \mathrm{~mm}$ ), covered with thermal insulation material, and finally placed into a wooden box, thus eliminating outside interferences. Figure 3 illustrates the entire experimental test cell. 


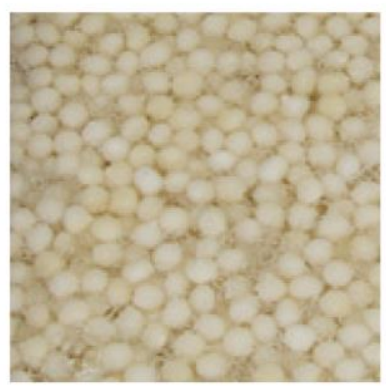

(a)

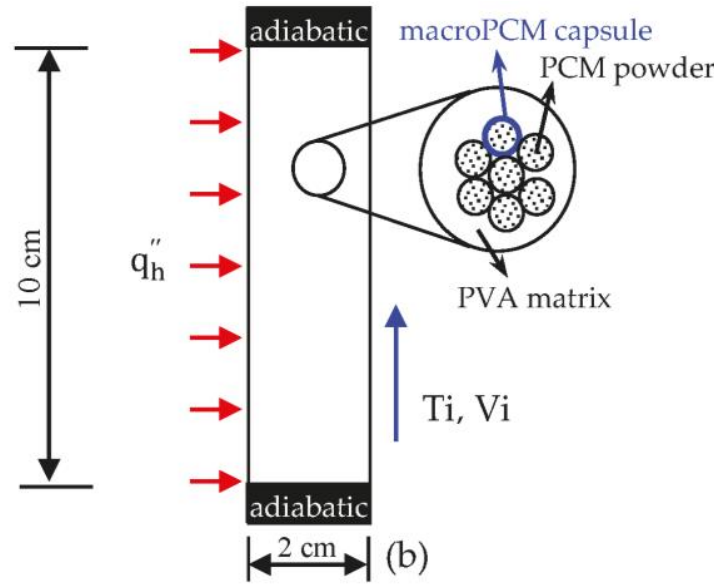

Figure 2. Investigated target and physical model: (a) Investigated target (macroPCM wall tile); (b) Physical model (macroPCM wall tile) (not to scale).

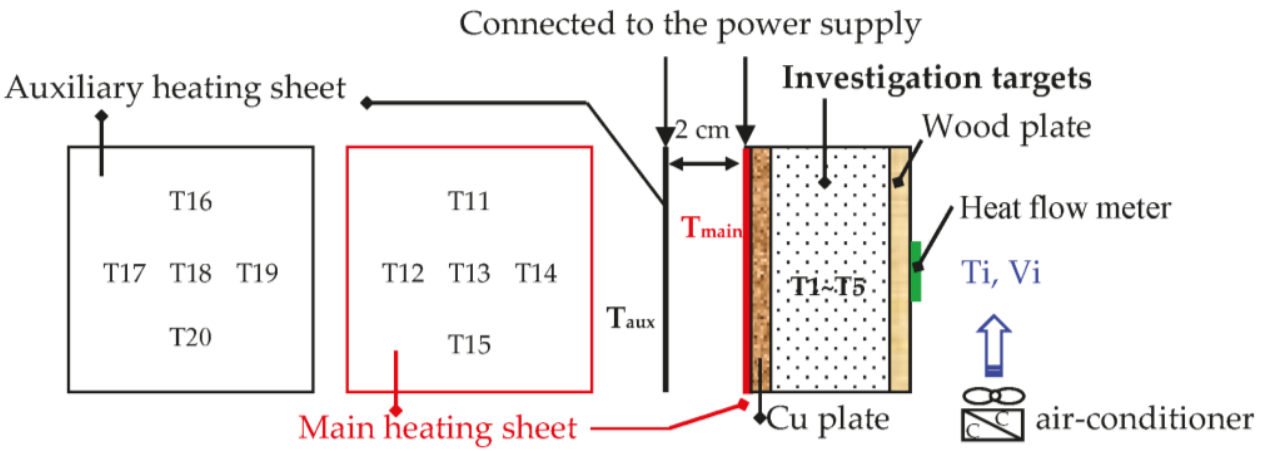

Figure 3. Experimental test cell (Tx: thermocouple locations) (not to scale).

We poured the macroPCM and polyvinyl acetate (PVA) into a $10 \mathrm{~cm} \times 10 \mathrm{~cm} \times 2 \mathrm{~cm}$ (W) balsa board box to obtain the investigation target (hereafter referred to as macroPCM + PVA, i.e., the PVA-based macroPCM wall tile mentioned above; Figure 2). The masses of macroPCM and PVA used were $95.9 \mathrm{~g}$ and $79.2 \mathrm{~g}$, respectively (macroPCM accounts for $55 \%$ of the investigation target by mass). To compare the thermal performances of similar materials, this experimental study included three other types of materials in addition to macroPCM + PVA. All investigation targets had identical volumes.

(1) Cement mortar was filled in a balsa board box to form an investigation target (hereafter, mortar).

(2) Both macroPCM (67.75 g) and cement mortar were tightly packed in a balsa board box to obtain an investigation target (hereafter, macroPCM + mortar).

(3) Both macro PCM and commercially available epoxy were filled into a balsa board box to obtain an investigation target (hereafter, macroPCM + epoxy). The masses of the materials used are $68.6 \mathrm{~g}$ for epoxy and $89.6 \mathrm{~g}$ for macro PCM (i.e., $56.6 \%$ of the investigation target).

\subsubsection{Hot Wall with Time-Variant Heat Flux, $q_{\text {in }}^{\prime \prime}$}

The hot wall with a time-variant heat flux, $q_{i n}^{\prime \prime}$ (on the left side of the experimental test cell in Figure 3), was made of a main heating sheet $(10 \mathrm{~cm} \times 10 \mathrm{~cm}$ mica heater) and attached to a $1 \mathrm{~mm}$ thick copper plate. The maximum electric power output of the main heating sheet was determined by the represented weather, as described in Section 2.4. The copper plate was included to evenly distribute the heat within the hot wall and to provide the required heat flux conditions for this experiment.

To reduce heat loss from the hot wall to the environment, an auxiliary heating sheet, a $10 \mathrm{~cm} \times 10 \mathrm{~cm}$ mica heater, was placed $2 \mathrm{~cm}$ from the main heating sheet. The input wattage to 
the main heating sheet was controlled to enable the hot wall to reach the set heat flux. The other input wattage to the auxiliary heating sheet was controlled to match the surface temperature $\left(T_{\text {aux }}\right)$ of the auxiliary heating sheet (average of T16-T20) to the surface temperature ( $\left.T_{\text {main }}\right)$ of the main heating sheet (average of T11-T15). This configuration was maintained to ensure that heat from the main heating sheet was conducted to the investigated target in an inward heat flow direction.

\subsubsection{Cold Wall with Convective Heat Transfer Conditions}

Air conditioning, located on the interior side of the investigation target, was used to simulate the indoor environment. The cold wall (on the right side in Figure 3) consisted of a wooden plate. Thermoregulated air from the air conditioner could flow over the cold wall with a set temperature $\left(T_{i}\right)$ and airflow velocity $\left(v_{i}\right)$.

\subsubsection{Temperature and Heat Flow Measurement}

Figure 3 presents the temperature measuring points. Five type-K thermocouples were placed on the surface of the main heating sheet and auxiliary heating sheet to determine $T_{\text {main }}$ and $T_{\text {aux }}$, respectively. Thermocouples were placed on the surface of the copper plate and wood plate to monitor the hot and cold wall temperatures, respectively. Heat flow inward to the interior was measured directly by heat flow meters. The device and data acquisition system included data acquisition units with $1 \mathrm{~Hz}$ data sampling rate (MX-100, YOKOGAWA, Tokyo, Japan), a PC, heat flow meters (MF-180, EKO Instruments, Tokyo, Japan), and AC/DC power supply units (GW Instek APS-1102, Good Will Instrument, New Taipei City, Taiwan).

\subsection{The MacroPCM Capsule Employed}

The macroPCM capsule, encapsulating $\mathrm{MPCM}$ powder, was manufactured by Microtek Laboratories, Inc., Dayton, OH, USA. The mean particle size on the capsule is typically $4 \mathrm{~mm}$, the specific gravity is about 0.9 , the capsules are about $80 \%$ PCM (paraffin, octadecane in this case) and $20 \%$ wall material. The nominal latent heat and the melting point should be similar to the micro-encapsulated octadecane which are $170-190 \mathrm{~J} / \mathrm{g}$ and $28^{\circ} \mathrm{C}$ respectively.

\subsection{Experiment Steps}

The main control parameters were the heat flux variation on the hot wall and the heat convection condition of the cold wall ( $q_{i n}^{\prime \prime}$ and $T_{i}$, respectively). The time-variant heat flux of the hot wall was based on the main heating sheet under the control of power from the power supply unit, mimicking the typical solar irradiation situation in the tropical region (Tainan City) in Taiwan. The convective condition of the cold wall were controlled by the constant airflow temperature $\left(T_{i}=25^{\circ} \mathrm{C}\right)$ and speed $(1.5 \mathrm{~m} / \mathrm{s})$ offered by an air conditioner, mimicking the typical indoor air environment. The initial temperature of the entire test cell was the same as that of the cold wall in the experiment.

To establish solar radiation conditions that were as realistic as possible, the time-variant heat flux $q_{i n}^{\prime \prime}(t)$ at the hot wall was obtained from meteorological data measured from June to August 2011 (summer season in Taiwan) for the average hourly amount of sunlight and was considered to be a sine function of time, as shown in Equation (1) and Figure 4. Figure 4 illustrates the heat flux input and measured meteorological data, both normalized by the respective peak values. The level of solar radiation immediately before sunrise and immediately after sunset is zero. Immediately after sunrise, the radiation begins to increase until a maximum $G_{s, o}$ is reached, after which the radiation decreases until sunset.

$$
q_{\text {in }}^{\prime \prime}(t)=G_{s, o} \sin \left(\frac{\pi t}{T}\right), 0 \leq t \leq T, T=10 \mathrm{~h}
$$

where $G_{s, 0}$ is the peak value $\left(400,600\right.$, and $\left.800 \mathrm{~W} / \mathrm{m}^{2}\right)$ of the heat flux input in the experiments. 


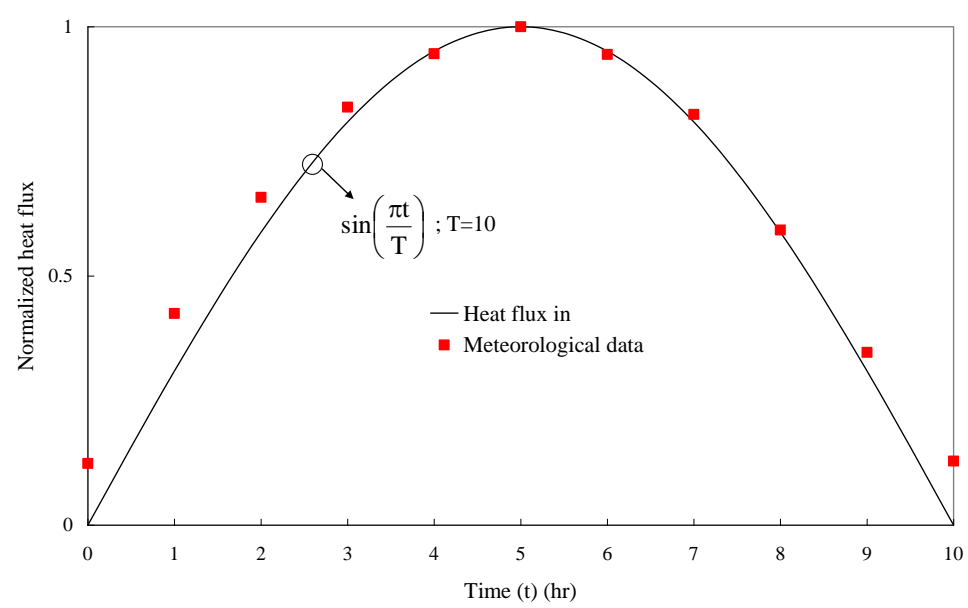

Figure 4. Normalized heat flux input and measured meteorological data.

Before starting, the overall temperature of the experimental test cell was set to $T_{i}$. The input power of the auxiliary heating sheet was adjusted to ensure that the surface temperature of the auxiliary heating sheet was equivalent to that of the main heating sheet. In some of the experiments, the surface temperature of each module was greater than $100{ }^{\circ} \mathrm{C}$ when $G_{s, 0}=1000 \mathrm{~W} / \mathrm{m}^{2}$, which does not lie within the applicable range of architectural engineering. Thus, the maximum value of $G_{s, o}$ for the modules was set to $800 \mathrm{~W} / \mathrm{m}^{2}$. The experiments for each module/test were repeated three times to confirm repeatability.

\subsection{Data Analysis}

The primary data included the temperature measured by thermocouples, the voltage, and the electric current from the power supply unit. The heat transfer was calculated from the data using the following formula:

(1) Input power, $\dot{q}_{\text {in }}$

Voltage $V(\mathrm{~V})$ and electric current $I(\mathrm{~A})$ values from the power supply unit were acquired with the data acquisition unit. From these values, the input power could be determined as $\dot{q}_{\text {in }}(\mathrm{W}), \dot{q}_{\text {in }}=V \cdot I$.

(2) Heat loss estimation, $\dot{q}_{\text {loss }}$

It was difficult to maintain the auxiliary heating sheet temperature matched to the main heating sheet temperature. The heat transfer between the main and auxiliary heating sheets had to be considered. The distance from the main heating sheet to the auxiliary heating sheet was $2 \mathrm{~cm}$. The heat transfer between the main and auxiliary heating sheets was divided into two conditions:

(a) $\mathrm{Ra}_{\mathrm{w}}<10^{3}, \overline{\mathrm{Nu}}_{\mathrm{w}}=1$, Equation (2) applied:

$$
\dot{q}_{\text {loss }}=\frac{k_{\text {air }} A\left(T_{\text {main }}-T_{\text {aux }}\right)}{W_{s}}+\frac{\sigma A\left(T_{\text {main }}^{4}-T_{\text {aux }}^{4}\right)}{\frac{1}{\varepsilon_{\text {main }}}+\frac{1}{\varepsilon_{\text {aux }}}-1}
$$

(b) $\quad \mathrm{Ra}_{\mathrm{w}}>10^{3}$, Equation (3) applied:

$$
\dot{q}_{\text {loss }}=\frac{\overline{\mathrm{Nu}}_{w} k_{\text {air }}\left(T_{\text {main }}-T_{\text {aux }}\right)}{W_{s}}+\frac{\sigma A\left(T_{\text {main }}^{4}-T_{\text {aux }}^{4}\right)}{\frac{1}{\varepsilon_{\text {main }}}+\frac{1}{\varepsilon_{\text {aux }}}-1}
$$

$\overline{N u}_{w}$ was calculated using Equation (4) [16]:

$$
\overline{\mathrm{Nu}}_{w}=0.18\left(\frac{\operatorname{Pr}}{0.2+\operatorname{Pr}} \operatorname{Ra}_{w}\right)^{0.29}
$$


Parameter range: $1<H / W_{s}<2,10^{-3}<\operatorname{Pr}<10^{5}, 10^{3}<\frac{\mathrm{Ra}_{w} \mathrm{Pr}}{0.2+\operatorname{Pr}}$.

Rayleigh numbers $\left(\mathrm{Ra}_{w}\right)$ were calculated using Equation (5):

$$
\operatorname{Ra}_{w}=\frac{g \beta_{T, a i r} \Delta T W_{s}^{3}}{\alpha_{a i r} v_{a i r}}
$$

where $k_{\text {air }}(\mathrm{W} / \mathrm{m} \cdot \mathrm{K})$ is the thermal conductivity of air, $T_{\text {main }}(\mathrm{K})$ is the surface temperature of the main heating sheet, $T_{\text {aux }}(\mathrm{K})$ is the surface temperature of the auxiliary heating sheet, $A$ is the area of heat transfer $(10 \times 10 \mathrm{~cm}), W_{s}$ is the distance between the main and auxiliary heating sheets $(2 \mathrm{~cm}), \varepsilon_{\text {main }}$ and $\varepsilon_{\text {aux }}$ are the respective surface emissivity (0.074) of the two heating sheets, $\sigma$ is the Stefan-Boltzmann constant $\left(5.67 \times 10^{-8} \mathrm{~W} / \mathrm{m}^{2} \mathrm{~K}^{4}\right), \beta_{T, a i r}(1 / \mathrm{K})$ is the thermal expansion coefficient of air, Pr is the Prandtl number of air, $\Delta T(\mathrm{~K})$ is the temperature difference between the main and auxiliary heating sheets, $\alpha_{a i r}\left(\mathrm{~m}^{2} / \mathrm{s}\right)$ is the thermal diffusion coefficient of air, and $v_{\text {air }}\left(\mathrm{m}^{2} / \mathrm{s}\right)$ is the kinematic viscosity of air.

(3) Modified input heat, $\dot{q}_{\text {corr }}$

After heat loss was calculated, $\dot{q}_{\text {loss }}(\mathrm{W})$ was subtracted from $\dot{q}_{\text {in }}(\mathrm{W})$ to obtain the modified input heat, $\dot{q}_{\text {corr }}(\mathrm{W})$. $\dot{q}_{\text {loss }}$ was positive when the auxiliary heating sheet temperature was lower than that of the main heating sheet, whereas it was negative when the auxiliary heating sheet temperature was higher than the main heating sheet temperature.

(4) Instantaneous fractional heat penetration, $Q_{r, i}$

$$
Q_{r, i}=\frac{q_{c}^{\prime \prime}(t)}{q_{h}^{\prime \prime}(t)}
$$

where $q_{h}^{\prime \prime}(t)$ and $q_{c}^{\prime \prime}(t)$ are the time-variant heat fluxes $\left(\mathrm{W} / \mathrm{m}^{2}\right)$ at the hot and cold walls, respectively.

(5) Time-averaged fractional heat penetration, $Q_{r, t}$

$$
Q_{r, t}=\frac{\int_{0}^{t} q_{c}^{\prime \prime} d t}{\int_{0}^{t} q_{h}^{\prime \prime} d t}
$$

\subsection{Experimental Uncertainty}

Uncertainties in the measured quantities for the present study were estimated to be $\pm 0.1{ }^{\circ} \mathrm{C}$ in the temperature, $\pm 0.05 \mathrm{~W}$ in the heat input measured by an electricity watt meter, and $\pm 2 \%$ in the heat flux measured by the heat flow meter. Following the uncertainty propagation analysis, the uncertainties for the deducted experimental results were estimated to be $0.92 \%-2.78 \%$ for the power in . Heat fluxes (out of the tested modules) to the interior and the sideway were measured synchronously. To reproduce the thermal behavior of the tested modules during service and to reduce the sideway heat flow, insulation was applied around the lateral of the modules. From the heat flow measurement within the peripheral insulation, the average accumulated heat loss of the cases with $G_{s, 0}=600 \mathrm{~W} / \mathrm{m}^{2}$, $T_{i}=25^{\circ} \mathrm{C}$, and $V_{i}=1.5 \mathrm{~m} / \mathrm{s}$ was $2.51 \%$ of the total inward heat transfer. All the heat losses are within an acceptable level. These errors are believed to be inconsequential to the results of the experiment.

\section{Results and Discussion}

\subsection{Heat Transfer Analysis of the Investigated Targets}

Figures 5-8 show temporal variations in temperature and heat flux at $G_{s, 0}=400 \mathrm{~W} / \mathrm{m}^{2}$ in different experimental modules (mortar, macroPCM + mortar, macroPCM + epoxy, and macroPCM + PVA). Because $q_{i n}^{\prime \prime}$ is the simulated solar heat gain, the temporal variations in temperature and heat flux both present sine-wave patterns within the experimental time range of $600 \mathrm{~min}(10 \mathrm{~h})$. In this experiment, the indoor side simulates an air-conditioned space, in which air temperature undergoes small changes in a zigzag pattern because of the on-off operation mode of the air conditioner compressor. To truly reflect the zigzag pattern of minor temperature changes in a real air-conditioned space, the results are illustrated in the form of unaveraged raw data; the hourly mean values are presented in the data description. 
Figure $5 \mathrm{~b}$ shows heat flux variations over time in the mortar module at $G_{s, 0}=400 \mathrm{~W} / \mathrm{m}^{2}$. Heat flux from the exterior into the cement mortar (i.e., heat flux in, $q_{i n}^{\prime \prime}$ ) peaks at $300 \mathrm{~min}$, whereas the mean heat flux from cement mortar into the interior side (i.e., heat flow out, $q_{\text {out }}^{\prime \prime}$ ) peaks at $323 \mathrm{~min}$, with a peak value of approximately $177.4 \mathrm{~W} / \mathrm{m}^{2}$. Compared to the peak $q_{i n}^{\prime \prime}$, the peak $q_{\text {out }}^{\prime \prime}$ shows a time lag of $23 \mathrm{~min}$, with a decrement factor $\left(=1-q_{o u t}^{\prime \prime} / q_{i n}^{\prime \prime}\right)$ of 0.56 . Stored heat flux peaks at $294 \mathrm{~min}$, with a peak value of $229 \mathrm{~W} / \mathrm{m}^{2}$, and it has almost no time lag relative to $q_{i n}^{\prime \prime}$. Figure 5 a shows the temperature variations over time in the mortar module. At $321 \mathrm{~min}$, a temperature maximum of $23.6^{\circ} \mathrm{C}$ occurs at the interior surface of the module (cold wall), with a temperature time lag (defined as the difference in time between when the peak heating occurs and when the peak cold wall temperature occurs) of $21 \mathrm{~min}$. Both the temperature differences across the cement mortar and time lag are minor. Because the thermal conductivity of cement mortar $(\sim 0.48 \mathrm{~W} / \mathrm{m} \cdot \mathrm{K})$ is moderate and the heat capacity is relatively low, there is very little sensible heat to absorb solar heat gain. This accounts for the smaller temperature differences within the cement mortar interior and the relatively high $q_{\text {out }}^{\prime \prime}$.

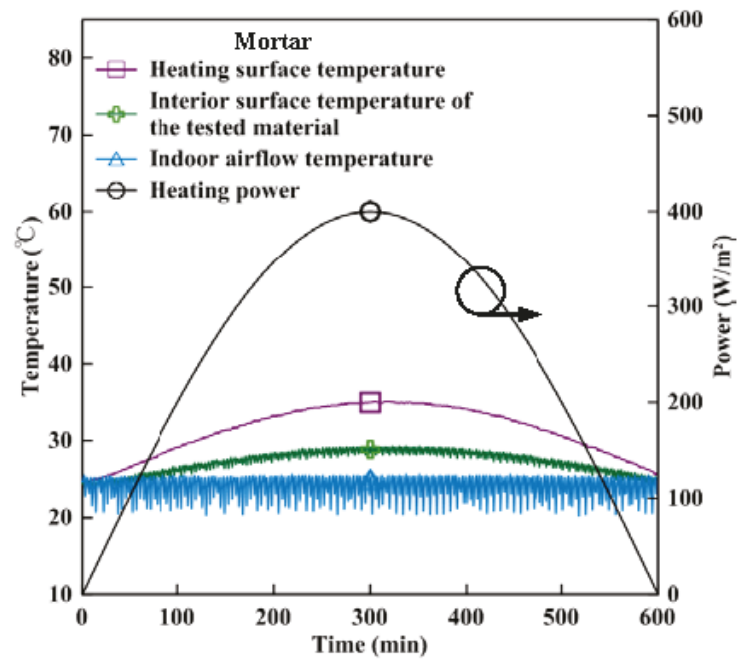

(a)

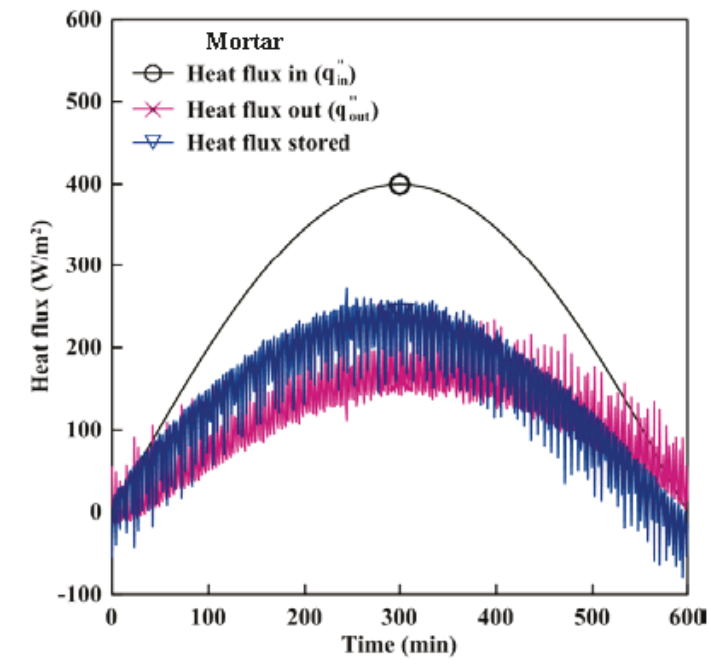

(b)

Figure 5. Heat transfer behavior of $\operatorname{mortar}\left(G_{s, 0}=400 \mathrm{~W} / \mathrm{m}^{2}\right)$ : (a) Temperature changes with time; (b) Heat flux changes with time.

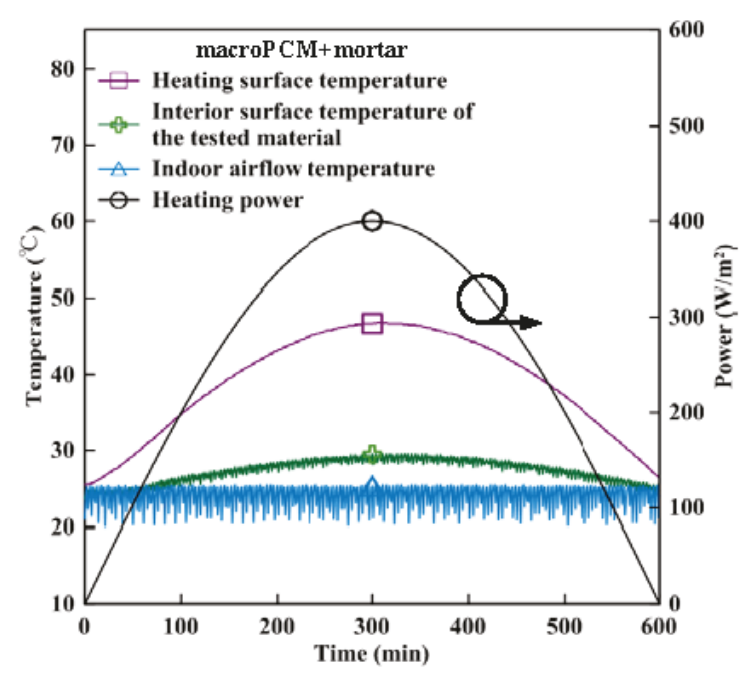

(a)

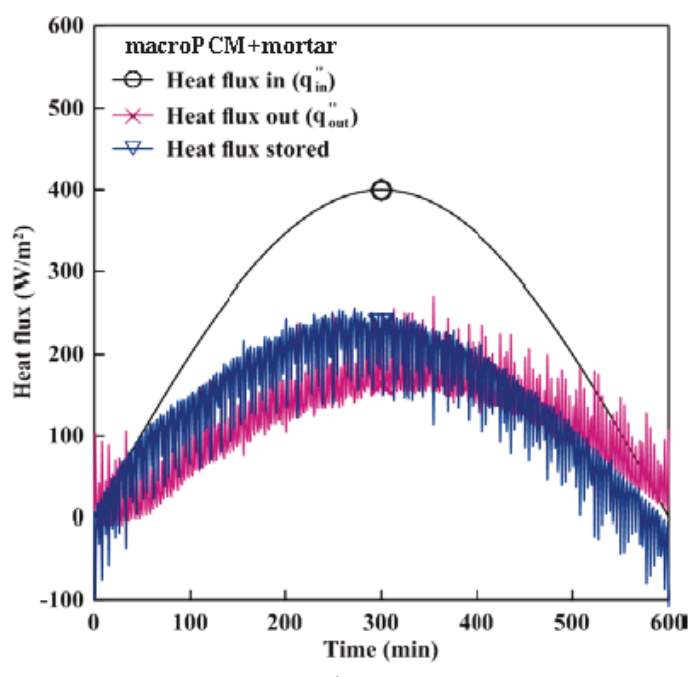

(b)

Figure 6. Heat transfer behavior of macroPCM $+\operatorname{mortar}\left(G_{s, o}=400 \mathrm{~W} / \mathrm{m}^{2}\right)$ : (a) Temperature changes with time; (b) Heat flux changes with time. 


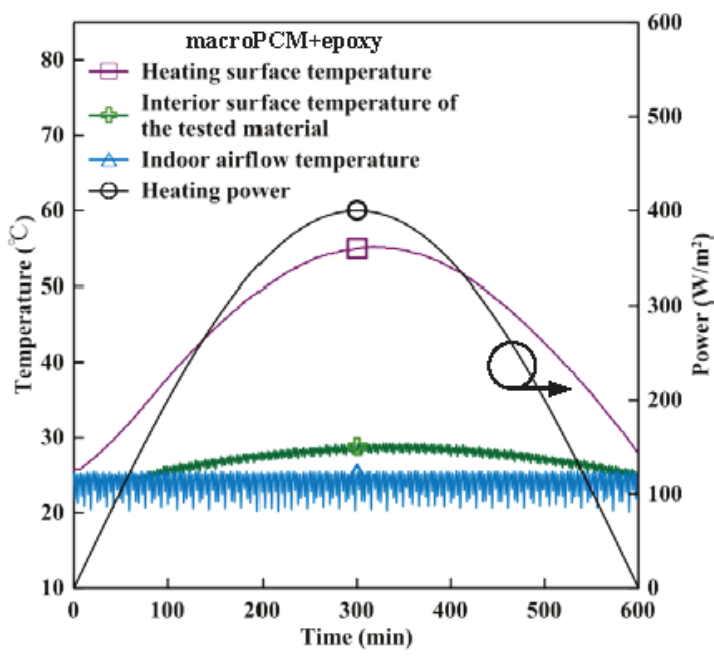

(a)

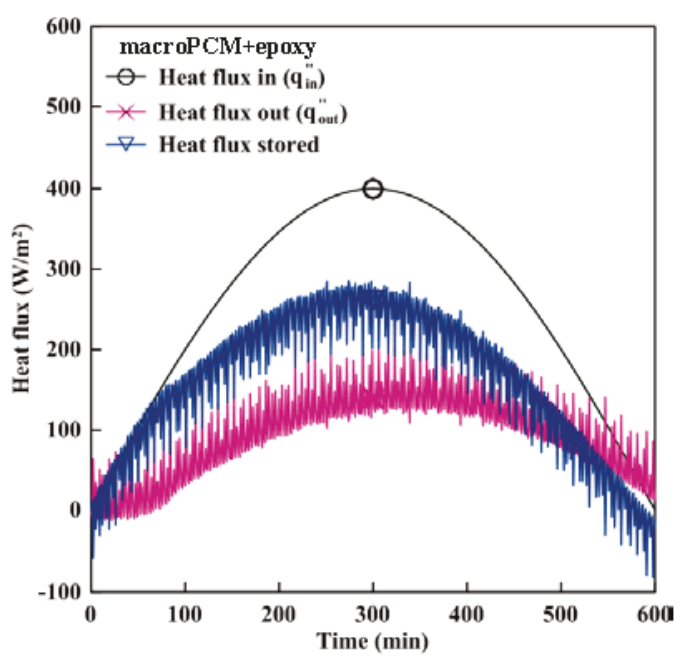

(b)

Figure 7. Heat transfer behavior of macroPCM $+\operatorname{epoxy}\left(G_{s, o}=400 \mathrm{~W} / \mathrm{m}^{2}\right)$ : (a) Temperature changes with time; (b) Heat flux changes with time.

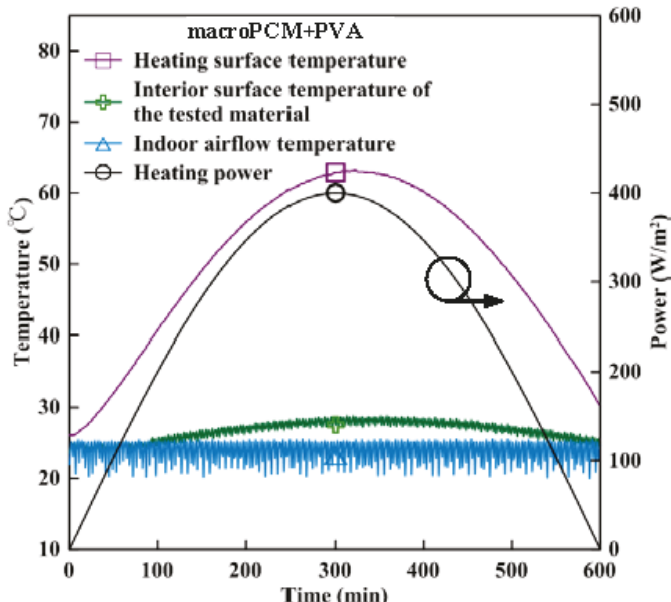

(a)

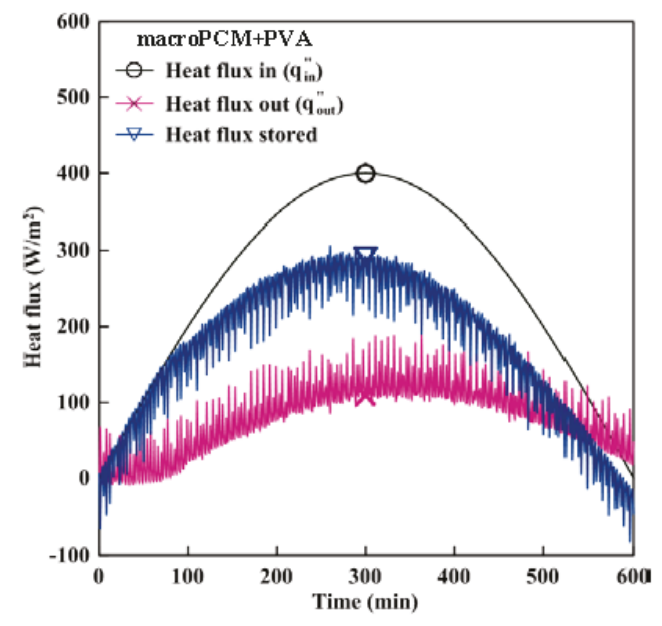

(b)

Figure 8. Heat transfer behavior of macroPCM $+\operatorname{PVA}\left(G_{s, o}=400 \mathrm{~W} / \mathrm{m}^{2}\right)$ : (a) Temperature changes with time; (b) Heat flux changes with time.

Next, we added macroPCM (67.75 g) into the cement mortar. The results obtained from the macroPCM + mortar module (Figure 6) show similar variation patterns compared to those observed in the cement mortar module (Figure 5). As shown in Figure 6b, the highest $q_{\text {out }}^{\prime \prime}$ of the macroPCM + mortar module is approximately $181.2 \mathrm{~W} / \mathrm{m}^{2}$, which occurs at $330 \mathrm{~min}$ (time lag $=30 \mathrm{~min}$ ). Compared with the mortar module, the macroPCM + mortar module has a larger time lag due to the energy storage of the incorporated PCM and a slightly increased peak heat flux (decrement factor $=0.55$ ).

Compared to the above two modules, the macroPCM + epoxy and macroPCM + PVA modules present different results, mainly because of the lower heat conductivities of epoxy $(\sim 0.3 \mathrm{~W} / \mathrm{m} \mathrm{K})$ and PVA $(\sim 0.16 \mathrm{~W} / \mathrm{m} \cdot \mathrm{K})$ and latent heat of macroPCM. Figure $7 \mathrm{~b}$ shows that when macroPCM $(89.6 \mathrm{~g}$, $56.6 \%$ mass fraction) was added into the epoxy, the highest $q_{\text {out }}^{\prime \prime}$ of the macroPCM + epoxy module is approximately $145.2 \mathrm{~W} / \mathrm{m}^{2}$ and occurs at $335 \mathrm{~min}$ (time lag $=35 \mathrm{~min}$ ). Compared with the above two modules, the macroPCM + epoxy module has a larger time lag but a significantly reduced heat flux (decrement factor $=0.64)$. Next, we added macroPCM $(95.9 \mathrm{~g}, 55 \%$ mass fraction) into PVA. 
In Figure $8 b$, it can be seen that the macroPCM + PVA module has its highest $q_{\text {out }}^{\prime \prime}$ of $126.6 \mathrm{~W} / \mathrm{m}^{2}$ at $340 \mathrm{~min}$ (time lag = $40 \mathrm{~min}$ ). Compared with the above three modules, the macroPCM + PVA module has a relatively large time lag but a significantly reduced heat flux (decrement factor $=0.68$ ).

Because macroPCM consists of spherical materials with a smooth surface and low density, it is difficult to plaster the mixture of macroPCM and mortar onto the wall with a spatula, resulting in inconvenience during construction. In contrast, macroPCM + epoxy and macroPCM + PVA have similar appearance and material strength as the tiles commonly used in indoor and outdoor decoration in buildings. Thus, the construction methods are fairly simple for the latter two materials, similar to the methods used for ordinary tiles: an adhesive layer is laid on the exterior surface of the structure, and macroPCM + epoxy or macroPCM + PVA is then plastered on directly to form the interior and exterior surfaces of the wall. The above procedure clearly shows the convenience of macroPCM + epoxy and macroPCM + PVA for construction. Taking into account the heat transfer analysis and construction convenience, macroPCM + epoxy and macroPCM + PVA are recommended as favorable materials for thermal insulation enhancement.

As shown in Figure 9, when the heating power is gradually increased from 400 to $800 \mathrm{~W} / \mathrm{m}^{2}$, the time lag from macroPCM + PVA is somewhat reduced but the decrement factor remains at 0.7, indicating its excellent heat flux insulation capability. In the following section, we investigated the transient thermal performance of macroPCM + PVA in relation to different levels of solar heat gain.

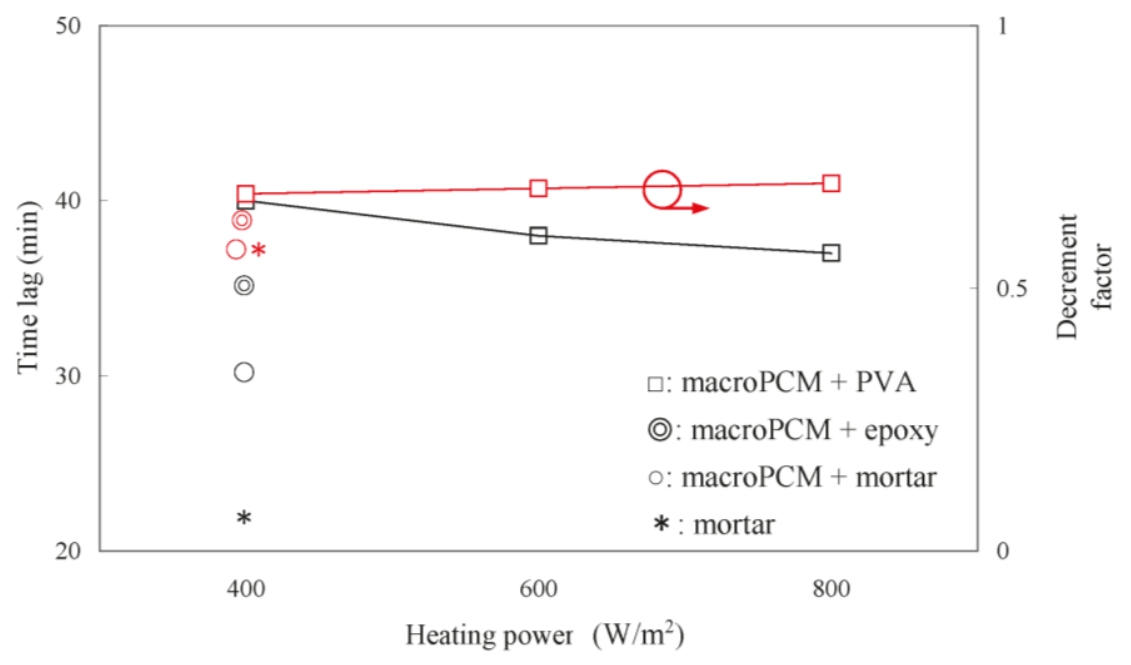

Figure 9. Time lag and decrement factor of experimental modules in relation to different levels of heating power.

\subsection{Dimensionless Heat Transfer Analysis of the MacroPCM + PVA Wall Tile}

Temporal variations of the instantaneous and the time-averaged fractional heat penetration through the interior wall, $Q_{r, i}$ and $Q_{r, t}$, are illustrated in Figure 10 for different heating powers. Within the first $100 \mathrm{~min}$ of the experiment, despite significantly low heating power, the operation of the air conditioner in an on-off mode results in a reduction in the indoor air temperature during a certain period of time. Thus, the experimental model produces a small heat flux into the indoor side, referred to as a slight subcooling effect. The results obtained from the first $100 \mathrm{~min}$ can be neglected, and readers are advised to focus on the phenomena observed after $100 \mathrm{~min}$.

To the thermal protection application, the instantaneous fractional heat flux across the module into the interior, $Q_{r, i}$, is of practical interest. It is evident from an overview of Figure 10a that the temporal trend of $Q_{r, i}$ exhibits a ramplike increase, then approaching the quasi-steady plateau and sharply the steady-state value of unity. The quasi-steady plateau comes from the latent heat effect of the macroPCM and time variation profile of the solar irradiation. Over an initial heating period, $Q_{r, i}$ displays an increase up to the quasi-steady value of about 0.2 , which amounts to only less than $20 \%$ of 
the incident heat flux at the heated wall, has penetrated across the macroPCM wall tile reaching the interior wall. The time interval from the beginning of the heating process down to the onset of the ramplike uprising of $Q_{r, i}$ can be viewed as an effective thermal-protection period of the macroPCM wall tile. For the time-averaged fractional heat penetration $Q_{r, t}$, as presented in Figure 10b, a one-stage temporal variation prevails after the experimental time $100 \mathrm{~min}$. After an initial period $(100 \mathrm{~min})$ of sharp variation with time, curves of the time-averaged fractional heat penetration $Q_{r, t}$ evolve drastically into a nonlinear time dependence with a markedly higher constant gradient. Another interesting message that can be inferred from Figure 10b is that within the whole heating process, the values of $Q_{r, t}$ still remain to be far less than unity, reflecting only small fraction of the time-averaged heat input as the heated wall is allowed to penetrate into the interior.

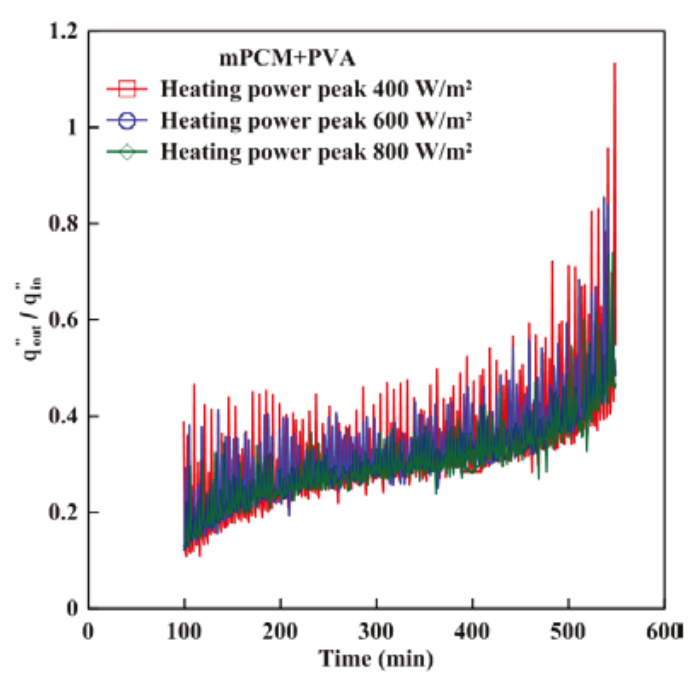

(a)

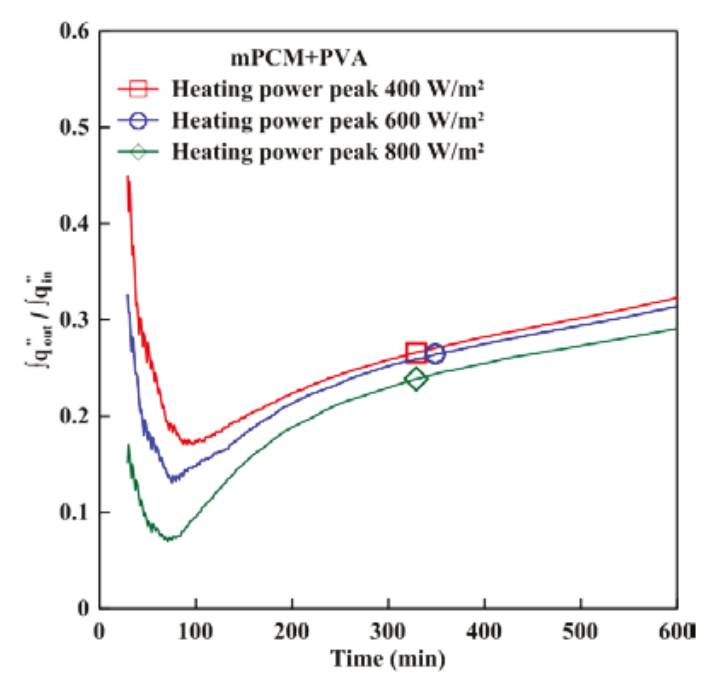

(b)

Figure 10. Histories of (a) instantaneous and (b) time-averaged, fractional heat penetration onto the interior side of the macroPCM + PVA wall tile with various heating powers.

\section{Conclusions}

This study integrated building material engineering, building construction practices, and heat transfer mechanism to develop a PVA-based macroPCM wall tile $(\mathrm{H} 10 \mathrm{~cm} \times \mathrm{L} 10 \mathrm{~cm} \times \mathrm{W}$ $2 \mathrm{~cm}$ ) containing a macro-encapsulated phase change material (macroPCM; core material: paraffin (octadecane); melting temperature: $28^{\circ} \mathrm{C}$ ) and polyvinyl acetate (PVA). The heat transfer and energy performances of the prepared material were analyzed experimentally. The main control parameters are the time-variation heat flux of the hot wall and heat convection condition of the cold wall, mimicking the typical outdoor solar radiation and indoor air-conditioned environment respectively. Time-variant heat flux at the hot wall was derived from measured meteorological data and is described as a sine function with peak values 400,600 , and $800 \mathrm{~W} / \mathrm{m}^{2}$. The convective conditions of the cold wall were set as airflow temperature $25^{\circ} \mathrm{C}$ and velocity $1.5 \mathrm{~m} / \mathrm{s}$.

The PVA-based macroPCM wall tile has adequate latent heat and thermal resistance. Thus, it increases the time lag of peak load and can effectively shift the summer peak demand. Additionally, the PVA-based macroPCM wall tile produces a lower indoor heat flux than other tested similar building materials (mortar, macroPCM + mortar, and macroPCM + epoxy). With respect to the appearance and material strength, the PVA-based macroPCM wall tile is a suitable material for indoor and outdoor decoration. Its construction method is quite simple, the same as that of ordinary tiles. According to the heat transfer analysis and as determined by considering the convenience of construction, the macroPCM + PVA decoration material is suitable for use in exterior walls to enhance the thermal performance. 
Acknowledgments: The authors gratefully acknowledge the support provided the Ministry of Science and Technology, Taiwan, ROC through Grant No. NSC 102-2221-E-006-165-MY3.

Author Contributions: Chi-Ming Lai conceived of and designed the experiments; Pin-Feng Liu and Chun-Ta Tzeng performed the experiments; Pin-Feng Liu and Yi-Pin Lin analyzed the data; and Chi-Ming Lai wrote the paper.

Conflicts of Interest: The authors declare no conflict of interest.

\section{References}

1. Zuo, J.; Li, W.; Weng, L. Thermal performance of caprylic acid/1-dodecanol eutectic mixture as phase change material (PCM). Energy Build. 2011, 43, 207-210. [CrossRef]

2. Wu, S.; Fang, G. Dynamic performances of solar heat storage system with packed bed using myristic acid as phase change material. Energy Build. 2011, 43, 1091-1096. [CrossRef]

3. Jaber, S.; Ajib, S. Novel cooling unit using PCM for residential application. Int. J. Refrig. 2012, 35, 1292-1303. [CrossRef]

4. Mandilaras, I.; Stamatiadou, M.; Katsourinis, D.; Zannis, G.; Founti, M. Experimental thermal characterization of a Mediterranean residential building with PCM gypsum board walls. Build. Environ. 2013, 61, 93-103. [CrossRef]

5. Lai, C.M.; Chen, R.H.; Lin, C.Y. Heat transfer and thermal storage behavior of gypsum boards incorporating micro-encapsulated PCM. Energy Build. 2010, 42, 1259-1266. [CrossRef]

6. David, D.; Kuznik, F.; Roux, J.J. Numerical study of the influence of the convective heat transfer on the dynamical behavior of a phase change material wall. Appl. Therm. Eng. 2011, 31, 3117-3124. [CrossRef]

7. Izquierdo-Barrientos, M.A.; Belmonte, J.F.; Rodríguez-Sánchez, D.; Molina, A.E.; Almendros-Ibáñez, J.A. A numerical study of external building walls containing phase change materials (PCM). Appl. Therm. Eng. 2012, 47, 73-85. [CrossRef]

8. Delgado, M.; Lázaro, A.; Mazo, J.; Marín, J.M.; Zalba, B. Experimental analysis of a microencapsulated PCM slurry as thermal storage system and as heat transfer fluid in laminar flow. Appl. Therm. Eng. 2012, 36, 370-377. [CrossRef]

9. Soares, N.; Costa, J.J.; Gaspar, A.R.; Santos, P. Review of passive PCM latent heat thermal energy storage systems towards buildings' energy efficiency. Energy Build. 2013, 59, 82-103. [CrossRef]

10. Osterman, E.; Tyagi, V.V.; Butala, V.; Rahim, N.A.; Stritih, U. Review of PCM based cooling technologies for buildings. Energy Build. 2012, 49, 37-49. [CrossRef]

11. Salunkhe, P.B.; Shembekar, P.S. A review on effect of phase change material encapsulation on the thermal performance of a system. Renew. Sustain. Energy Rev. 2012, 16, 5603-5616. [CrossRef]

12. Hasse, C.; Grenet, M.; Bontemps, A.; Dendievel, R.; Sallee, H. Realization, test and modelling of honeycomb wallboards containing a Phase Change Material. Energy Build. 2011, 43, 232-238. [CrossRef]

13. Mahmoud, S.; Tang, A.; Toh, C.; AL-Dadah, R.; Soo, S.L. Experimental investigation of inserts configurations and PCM type on the thermal performance of PCM based heat sinks. Appl. Energy 2013, 112, 1349-1356. [CrossRef]

14. Schossig, P.; Henning, H.M.; Gschwander, S.; Haussmann, T. Micro-encapsulated phase-change materials integrated into construction materials. Sol. Energy Mater. Sol. Cells 2005, 89, 297-306. [CrossRef]

15. Lai, C.M.; Hokoi, S. Thermal performance of an aluminum honeycomb wallboard incorporating microencapsulated PCM. Energy Build. 2014, 73, 37-47. [CrossRef]

16. Incropera, F.P.; DeWitt, D.P.; Bergman, T.L.; Lavines, A.S. Principles of Heat and Mass Transfer, 7th ed.; John Wiley \& Sons: Hoboken, NJ, USA, 2013. 